\title{
LA BIOJURÍDICA: SUMA \\ DE LA BIOÉTICA Y DE LA ACCIÓN DE TUTELA
}

Doctor en Derecho Universidad Javeriana Director del Grupo de Investigación "Diego de

Torres y Moyachoque, Cacique de Turmequé"

Profesor Investigador

Universidad de La Sabana, Chía, Colombia.

\author{
HERNÁN ALEJANDRO OLANO GARCÍA*
}

\section{RESUMEN}

El autor presenta su punto de vista personal acerca de algunos aspectos del derecho constitucional que tocan a la bioética y se convierten en una nueva área jurídica muy usual en Colombia pero inexplorada desde la ciencia del Derecho: La biojurídica.

\section{PALABRAS CLAVE}

Bioética, Derecho a la Vida, Derecho a la Salud, Utilitarismo, Personalismo, Eutanasia.

\section{RESUMEN}

El autor presenta su punto de vista personal acerca de algunos aspectos del derecho constitucional que tocan a la bioética y se convierten en una nueva área jurídica muy usual en Colombia pero inexplorada desde la ciencia del Derecho: La biojurídica.

\section{PALABRAS CLAVE}

Bioética, Derecho a la Vida, Derecho a la Salud, Utilitarismo, Personalismo, Eutanasia.

* El doctor Hernán Alejandro Olano García, n. Santiago de Tunja, 1968. Abogado, especializado en Derecho Constitucional, Derechos Humanos, Derecho Canónico, Bioética, Docencia Universitaria y Liderazgo Estratégico Militar. Magíster en Relaciones Internacionales y Magíster en Derecho Canónico, Doctor Magna Cum Laude en Derecho Canónico y PhD H.C. en Historia. Becario de la Fundación Carolina para estancia Postdoctoral en el Departamento de Derecho Constitucional de la Universidad de Navarra para desarrollar su investigación sobre “Choque de Trenes”. Profesor Asociado en la Universidad de La Sabana de Chía, Colombia. Investigador de la Cátedra Garrigues de derecho Global - Universidad de Navarra. Vicecónsul Honorario de la República de Chipre en Colombia. Miembro de la Academia Colombiana de Jurisprudencia y del Centro Colombiano de Derecho Procesal Constitucional. Fue Secretario General de la Corte Constitucional de Colombia, Director General Jurídico del Ministerio del Interior y Asesor del Despacho. Grupo de Investigación en Derecho Constitucional "Diego de Torres y Moyachoque, Cacique de Turmequé", categoría "A" por Colciencias. Línea de Investigación en Historia de las Instituciones. http://hernanolano.googlepages.com Correo electrónico hernan.olano@unisabana. edu.co Dirección: Universidad de La Sabana, Km. 21 Autopista Norte, Costado Occidental, Chía, Cundinamarca, Colombia. 
a bastísima producción jurisprudencial de la Corte Constitucional desde el 17 de febrero de 1992, fecha de su instalación oficial, prácticamente desborda los límites de estudio normal sobre un tema concreto y mucho más en relación con el derecho a la salud, que toca todos los aspectos de la bioética y de su relación con la acción de tutela, en lo que se denomina la biojurídica.

Tomando como base algunas consideraciones efectuadas por la doctora Ilva Myriam Hoyos y por los profesores Tomás Melendo, Urbano Ferrer, Jorge Arregui, Robert Spaemann y José Luis del Barco, hemos efectuado este escrito para los alumnos de la Facultad de Medicina de la Universidad de La Sabana.

Lainvestigaciónconsereshumanos, lostransplantes de órganos, la manipulación del código genético, la fecundación asistida, la prolongación artificial de la vida y otras posibilidades de la técnica, han suscitado problemas jurídicos desconocidos hasta ahora o tratados con la simpleza de lo artificial o superfluo. La necesidad de explicarlos adecuadamente y resolverlos de una forma adecuada hizo surgir la Bioética, centrada según Leonardo Polo', en el "estudio de los problemas éticos que plantea el desarrollo de las diferentes ciencias y tecnologías que pueden aplicarse $-y$ por tanto influir o modificar-a la vida humana".

Precisamente José Luis del Barco, ha querido establecer que laBioética no es una moral a la altura de los tiempos, ni sus valores son descubrimientos recientes llamados a sustituir los viejos principios por otros nuevos capaces de orientar en la complejidad del presente. "La bioética es sencillamente ética, sabiduría práctica sobre el modo de evitar que la vida humana se malogre. Lo realmente nuevo son las extraordinarias posibilidades técnicas de inmiscuirse en la vida, bien para promoverla y prestarle auxilio, bien para manipularla, degradarla o aniquilarla."2

La nueva especialidad creada sobre la Bioética, es decir, la Biojurídica, busca el discernimiento de la eticidad de las acciones que sobre la vida humana comprometen al Derecho.

Como se sabe, el término "Bioética" fue utilizado por primera vez en 1971 por Van Rennsselaer Potter, profesor de Oncología de la Universidad de Wisconsin, aunque el interés por el tema es anterior a nivel médico, pero nuevo a nivel jurídico.

En 1969 se fundó lo que hoy es el Hastings Center por Willard Cayling y Daniel Callahan, con el nombre de Institute of Society, Ethics and the Life Sciences. En 1972 el doctor Andre Hellegers, especialista en fisiología del John Hopkings Hospital de Baltimore, creó el primer instituto con la expresión Bioética, el The Joseph and Ross Kennedy Institute for the Study of Human Reproduction and Bioethics y, en Europa, el primer centro importante fue creado en 1975 en Barcelona con el nombre de Instituto Borja.

Hoy en día, existen muchísimas instituciones como el Institute of Medical Ethics de Londres, el Centre d'Etudes Bioéthiques de Bruselas, el Instituto voor Gezondheitsethiek de Holanda, el Centro de Estudios Bioéticos de la Universidad de Roma, etc.

Sin embargo, en el campo del Derecho y su relación con la Bioética, es decir la Biojurídica, los estudios son reducidos aunque coinciden en considerar la promoción y desarrollo de la persona y su dignidad como criterio de lo moralmente lícito. Además, algunos han logrado que no se hable de que el Derecho es por la persona sino para la persona, lo que significa el reconocimiento de su dignidad.

Ilva Myriam Hoyos ha dicho que "si la Bioética es hacerle justicia a la vida, y si la justicia es darle

1 POLO, Leonardo. Presente y Futuro del Hombre, Rialp, Madrid, 1993, página 135. Citado por DEL BARCO, José Luis en: Presentación del Anuario Filosófico Volumen XXVII/1, Universidad de Navarra, página 10.

2 DEL BARCO, José Luis en: Presentación del Anuario Filosófico Volumen XXVII/1, Universidad de Navarra, página 10.

3 HOYOS CASTANE DA, Ilva Myriam. Los Principios de la Declaración del Genoma Humano y los Derechos Humanos. En: Pensamiento y Cultura \# 4, 2001, Universidad de La Sabana, página 154. 
a cada quien su derecho, el derecho o lo justo es aquello que se adecua a la persona en razón de su dignidad. De ahi que la fórmula clásica de la justicia pueda interpretarse-así lo hace Ciceróncomo darle a cada uno su dignidad". 3

Esos son conceptos que nos hacen pensar en la necesidad de asegurar los valores de la Bioética, de la Vida y de la Ética, por decirlo de otra manera, a través de la Biojurídica, para con ella, hacer posible la comunidad.

"Y hablo tanto de la vida de las personas como de la vida de las comunidades, como de la vida de los pueblos, así como de la vida del ecosistema. A la vida humana le es sustancial la ética, porque la vida sin crecimiento no es vida. Y la vida humana es ética porque ésta es más vida. En esta perspectiva, toda ética no sólo requiere de la vida, sino que la acrecienta. La ética de la vida, la Bioética, es por tanto, consustancial a toda ética, porque sin vida no hay ética que valga. Y si la Bioética - como lo afirmó José Luis del Barcoes "hacer justicia a la vida, dar al vivir lo que es suyo" y si la justicia es la acción de darle a cada quien lo suyo, y si lo suyo es lo justo o el derecho, la Bioética requiere de lo justo."

Aunque Colombia ha incorporado a su legislación interna una serie muy extensa de documentos internacionales, que hacen hoy día parte del llamado Bloque de Constitucionalidad, no podemos desconocer la importancia de los mismos para la construcción de la Biojurídica.

Entre esos DOCUMENTOS BÁSICOS se encuentran:

1. Carta de la Organización de Naciones Unidas. Artículos 1, 2, 55 y 56. (1945).

2. Carta de la Organización de Estados Americanos. Artículos 5, 28 a 31. (1948).

3. Declaración Universal de los Derechos Humanos. (1948).
4. Declaración de los Derechos del Hombre y del Ciudadano. (1789).

5. Declaración Americana de los Derechos y Deberes del Hombre. (1948).

6. Carta Internacional Americana de Garantías Sociales y de los Derechos Sociales del Trabajador. (1947).

7. Convención Europea de Salvaguardia de los Derechos del Hombre y de las Libertades Fundamentales. (1950).

8. Carta Social Europea. (1961).

9. Convención Relativa a la Lucha contra las Discriminaciones en la esfera de la Enseñanza. (ONU, 1960).

\section{CARTAS INTERNACIONALES DE DERECHOS HUMANOS}

1. Pacto Internacional de Derechos Civiles y Políticos (Ley 74 de 1968).

2. Protocolo Facultativo del Pacto Internacional de Derechos Civiles y Políticos (Ley 74 de 1968).

3. Pacto Internacional de Derechos Económicos, Sociales y Culturales (Ley 74 de 1968).

4. Convención Americana Sobre Derechos Humanos "Pacto de San José de Costa Rica" (Ley 16 de 1972).

\section{NORMAS DEL DERECHO INTERNACIONAL HUMANITARIO}

1. Convenio de Ginebra I - del 12 de Agosto de 1949 para aliviar la suerte que corren los heridos y los enfermos de las fuerzas armadas en campaña (Ley 5 de 1960). 
2. Convenio de Ginebra II - del 12 de Agosto de 1949 para aliviar la suerte que corren los heridos, los enfermos y los náufragos de las fuerzas armadas en el mar (Ley 5 de 1960).

3. Convenio de Ginebra III - del 12 de Agosto de 1949 relativo al trato debido a los prisioneros de guerra (Ley 5 de 1960).

4. Convenio de Ginebra IV - del 12 de Agosto de 1949 relativo a la protección debida a las personas civiles en tiempo de guerra (Ley 5 de 1960).

5. Protocolo I Adicional a los Convenios de Ginebra del 12 de Agosto de 1949 relativo a la protección de las víctimas de los conflictos armados internacionales.

6. Protocolo II Adicional a los Convenios de Ginebra del 12 de Agosto de 1949 relativo a la protección de las víctimas de los conflictos armados sin carácter internacional.

\section{NORMAS SOBRE EL} DERECHO A LA VIDA Y A LA INTEGRIDAD

1. Convención para la prevención y el castigo del crimen de Genocidio (Ley 28 de 1959).

2. Convención contra la tortura y otros tratos o penas crueles, inhumanas o degradantes (Ley 76 de 1986).

\section{NORMAS SOBRE EL DERECHO A LA SEGURIDAD SOCIAL Y A LA SALUD}

1. OIT, Convención sobre el trabajo de las mujeres antes y después del parto (Ley 129 de 1931).

2. OIT, Convención relativa a las indemnizaciones por accidentes de trabajo en la agricultura (Ley 129 de 1931).

3. OIT, Convención relativa al empleo del albayalde en la pintura (Ley 129 de 1931).
4. OIT, Convención sobre examen médico obligatorio de los niños y de los jóvenes que trabajan a bordo de las naves (Ley 129 de 1931).

5. OIT, Convención acerca de la indemnización por accidentes de trabajo (Ley 129 de 1931).

6. OIT, Convención sobre reparación de las enfermedades resultantes del trabajo (Ley 129 de 1931).

7. OIT, Convención relativa al seguro contra enfermedades de los trabajadores de la industria, del comercio y de los sirvientes domésticos (Ley 129 de 1931).

8. Convenciónsobreelsegurocontraenfermedades de los trabajadores agrícolas (Ley 129 de 1931).

9. OIT, Convenio \#62 relativo a las prescripciones de seguridad en la industria de la edificación (Ley 23 de 1967).

10. OIT, Convenio \#136 relativo a la protección contra los riesgos de intoxicación por el benceno (Ley 44 de 1975).

Sumado a ellos la Declaración Universal del Genoma Humano y de los Derechos Humanos, adoptada por unanimidad y por aclamación en la 29a sesión de la Asamblea General de la UNESCO, el 11 de noviembre de 1997, y adoptada también por la Asamblea General de las Naciones Unidas el 9 de diciembre de 1998, en el marco de la conmemoración del cincuentenario de la Declaración Universal de los Derechos Humanos del 10 de diciembre de 1948.

La Declaración Universal de 1997, según palabras de la doctora Ilva Hoyos, no desconoce los peligros de los avances biocientíficos y biotecnológicos que pueden llevar, incluso, a que se manipule la herencia del hombre y se modifique el genoma humano. Su pretensión no es, sin embargo, la de rechazar esas investigaciones cientificas, sino, en cierto sentido propiciarlas, porque "abren inmensas perspectivas -así se lee en el último considerando del Preámbulo de la Declaraciónde mejoramiento de la salud de los individuos y 
de toda la humanidad" y de enmarcarlas en el respeto a la "dignidad, la libertad y los derechos de la persona humana, así como la prohibición de toda forma de discriminación fundada en las características genéticas".

Continua la doctora Hoyos con tres precisiones en torno a la Declaración Universal sobre el Genoma Humano, que pueden leer en "Pensamiento y Cultura” \# 4, 2001, páginas 148-149, Revista de la Universidad de La Sabana.

La Acción de tutela ha sido la innovación con alcances jurídicos, políticos y sociales más dinámicos de la Constitución, ya que permite a toda persona reclamar ante los jueces la protección inmediata de sus derechos constitucionales fundamentales, cuando quiera que estos resulten violados o amenazados por la acción o la omisión de cualquier autoridad pública, e inclusive con respecto a particulares encargados de la prestación de un servicio público, cuya conducta afecte grave y directamente el interés colectivo.

Como lo dijo en su momento el Presidente César Gaviria:

"El principal peligro de la tutela no es que se use, sino que no se utilice para proteger los derechos que han nacido o han sido ampliados con la Constitución de 1991. Ese es el gran riesgo, que haya impunidad ante la arbitrariedad, que las vías del derecho no sirvan para resolver los conflictos, quelos derechos sequeden congelados en la fría letra de las normas y nunca salgan a la calle para vivir en la realidad, que el derecho vaya por un lado y los hechos por el otro".

Sin embargo, la "seducción utilitaria" llegaría a nuestra Corte Constitucional y allí encontramos la relación entre la Bioética y la Acción de Tutela; es que la primera, sin proponérselo, ha sido la ciencia que más ha aportado al desarrollo jurisprudencial del Estado. Sin embargo, el utilitarismo de la mayoría, frente a un débil personalismo de los salvamentos de voto, ha sido lo que ha producido inicialmente una cierta apariencia de racionalidad a las sentencias de la Corte Constitucional.

Como diría José Luis el Barco, “al caminante extraviado le promete esta guía para salir de cualquier laberinto: mejorar el mundo. La moralidad de la acción no se ha de buscar, pues, en ella misma, sino en sus consecuencias para la marcha del universo... Además, el utilitarismo se amolda perfectamente al modelo de acción técnica dominante, pues el punto e vista moral no limita -más bien aconseja- la orientación y planificación técnica y racional de la acción. Junto a ello, parece estar especialmente capacitado para proporcionar orientación en épocas de cambios vertiginosos, con sus vaivenes e incertidumbres, pues renuncia a definir la justicia y la bondad de forma no funcional. El único patrón de medida de lo justo y de lo bueno es su contribución a la marcha del mundo. Finalmente, la moral utilitaria hace superflua la idea de Dios.",5

Por ejemplo, la Corte Constitucional se ha referido al tema de la vida, los derechos del nasciturus, la maternidad, la salud, la salubridad pública y el medio ambiente, la asistencia médica, la seguridad social, la ética, los médicos, las historias clínicas, la eutanasia, el genocidio, los minusválidos, los dementes, los centros hospitalarios, las historias clínicas, el aborto y la detención hospitalaria, entre otras y en todas ellas, desafortunadamente se evidencia un punto de vista utilitarista frente al ser y a su dignidad, así Carlos Agapito Gaviria Díaz haya expresado que "lo que la Corte Constitucional de Colombia ha hecho no es, como lo pretenden sus críticos intonsos, una apología de la muerte sino un rescate del sujeto moralmente responsable, digno y libre", con el siguiente argumento de la

5 DEL BARCO COLLAZOS, José Luis. La Seducción Utilitaria. En: Anuario Filosófico XXVII, 1994, Universidad de Navarra, Pamplona, páginas 90 - 91

6 GAVIRIA DÍAZ, Carlos Agapito. Fundamentos Ético-Jurídicos para despenalizar el homicidio piadoso-consentido. En: Jurisdicción Constitucional de Colombia. La Corte Constitucional 1992-2000, Realidades y Perspectivas. Editado por la Fundación Konrad Adenauer y la Escuela Judicial Rodrigo Lara Bonilla, Bogotá, D.C., febrero de 2001, página 232. 
filosofía liberal que profesa: "Sócrates y Cristo son paradigmas de moralidad. El primero juzgó mejor morir que vivir sin dignidad: fuera de Atenas, o en ella pero renunciando a formular sus impertinentes preguntas, como se lo propuso el Tribunal de los Quinientos. Y el segundo, si es que no interpretamos correctamente su mensaje, estimó bueno morir para salvar al hombre. Una y otra conducta permiten inferir que no siempre conservar la vida es lo mejor."7

A esto contestó la Universidad de La Sabana, cuando se produjo el fatídico fallo C-239 de 1997, en los siguientes términos:

La Universidad de La Sabana, el 6 de junio de 1997, publicó en el diario El Tiempo, un "Manifiesto por la Vida", que recoge la visión personalista del hombre y la trascendencia de su dignidad, en los siguientes términos:

"1. La Universidad de La Sabana, ante el pronunciamiento de la mayoría de la Corte Constitucional que parece haber introducido en el país, para ciertos casos, la práctica legalizada de la eutanasia, invita a todos los colombianos, creyentes y no creyentes, a hacer una reflexión serena en torno a esa permisividad contraria al más importante de los derechos y responsabilidades detodohombreyaemprender oportunamente la correspondiente acción que puede llegar a corregir ese gravísimo extravio de nuestro ordenamiento jurídico. Aunque la fecha-junio 3 de 1997-no se ha conocido aún el texto de la providencia que dará vía libre a ese crimen secularmente conocido como "homicidio piadoso", por las declaraciones del Ponente y del mismo Presidente de la Corte, nos es dado concluir -por disfortuna- que sí se ha producido ya un tal oscurecimiento en nuestro sistema jurídico penal colombiano.

2. Se ha dicho que tal concesión se ha de hacer en nombre del pluralismo. El pluralismo es una conquista de la civilización de occidente, y es la expresión política e ideológica de la más pura libertad: nada tiene que ver con la derogación implícita o explícita del respeto personal o estatal al sagrado derecho de vivir.

3. Se ha querido involucrar asimismo - mancillando aquél pluralismo- a las religiones y a los creyentes, como únicos opositores a la pretermisión del derecho natural a la vida $-y$ por razones de su religión y de su fe-al tiempo que se olvida que el mandato constitucional vigente consagra no sólo la inviolabilidad de la vida humana, sino también la prohibición de la pena de muerte.

4. Los colombianos hemos sido puestos, entonces, frente a la opción imposible: o la cultura de la muerte, o la cultura de la vida. Si escogiéramos la primera, franquearíamos la barrera del respeto a la dignidad de la vida humana, y desconoceríamos el valor absoluto de ésta. A la licencia para matar enfermos terminales sucedería de inmediato, además, la que permitiría hacer lo mismo con los niños concebidos mediante violación carnal o con defectos físicos detectables. $\mathrm{Ni}$ estamos ni queremos estar preparados para una convivencia legal impune con tal género de barbarie. ¡Muy amargos se harían nuestros dias, y muy vana se volvería nuestra otra real lucha por establecer en la nación ese esquivo reinado de la paz, que con tanto empeño buscamos desde tiempos muy antiguos!.

5. LaUniversidad, en el ámbitoquelecorresponde, y en coherencia con su destino al servicio del país, estaría dispuesta a iniciar desde la academia, si llegare el caso, un movimiento conducente a solicitar la reforma de la Constitución Nacional con el fin de conseguir la plena restitución del derecho inviolable a tener, desde la concepción y por todas las épocas de la vida, el curso natural del más grande don recibido de Dios."

Como puede verse, la Corte Constitucional con la Sentencia C-239 de 1997, estableció una licencia para matar de modo irresponsable, desconociendo

7 GAVIRIA DIAZ, Art. Cit., página 228. 
evidentes criterios morales, éticos y jurídicos, al resolver una demanda contra el artículo 326 del Código Penal, con una votación de seis a tres, con ponencia de Carlos Gaviria Díaz apoyada por los Magistrados Antonio Barrera, Jorge Arango, Eduardo Cifuentes, Alejandro Martínez y Fabio Morón.

El tema se torna conflictivo cuando la Corte estudia en ese fallo la relación existente entre el derecho a la vida y la autonomía, a la luz de nuestra Carta.

El argumento central de la Corte Constitucional, en tan cuestionada sentencia, es que del derecho a vivir en forma digna se deriva un derecho a morir dignamente, del que sería titular no toda persona, sino el enfermo terminal que padezca intensos dolores o sufrimientos ocasionados por enfermedad grave o incurable, la cual le habilitaría para determinar libremente si prefiere vivir o morir.

Considera, de manera expresa, la Corte Constitucional: "la decisión de cómo enfrentar la muerte adquiere una importancia decisiva para el enfermo terminal, que sabe que no puede ser curado, y que por ende no está optando entre la muerte y muchos años de vida plena, sino entre morir en condiciones que él escoge o morir poco tiempo después en circunstancias dolorosas que juzga indignas. El derecho fundamental a vivir en forma digna implica entonces el derecho a morir dignamente, pues condenar a una persona a prolongar por tiempo escaso su existencia, cuando no lo desea y padece profundas aflicciones, equivale no solo a un trato cruel e inhuman, prohibido por la Carta (artículo 12 de la Constitución Política), sino una anulación de su dignidad y de su autonomía como sujeto moral. La persona quedaría reducida a un instrumento para la preservación de la vida como valor abstracto.",

Dice la doctora Ilva Myriam Hoyos que si el Estado se arroga esa facultad de determinar si una persona vive o muere, se lesionaría el que para la Corte es el derecho fundamental y principal del ordenamiento jurídico: el libre desarrollo de la personalidad. Para el Alto Tribunal Constitucional, la personalidad se desarrolla en el caso de que el enfermo terminal decida la muerte, porque "hay circunstancias que rodean su vida que no la hacen deseable ni digna de ser vivida”.

Se comparte una apreciación de la doctora Hoyos, cuando dice que en sana lógica jurídica debe afirmarse que el mandato de muerte es contrario a derecho y que está viciado de nulidad absoluta, ya que "en el caso extremo de llegar admitirse la juridicidad de este mandato, surge el problema de saber cuál es el derecho que tiene el enfermo que sufre una lesión grave e incurable que le produzca intensos sufrimientos: ¿podría decirse que tiene el derecho de ser muerto, porque el tercero tendría la obligación de proveer esa muerte?"

De ahí, pareciera que la Corte sugiere que la dignidad humana no es una realidad objetiva, sino que varía según las circunstancias que rodean la vida o las valoraciones o las estimaciones que sobre ella se realicen.

Según la Sentencia C-239 de 1997, la libertad parecería no tener límite alguno y no lo serían ni los deberes propios ni los deberes de los demás. Según la Carta Política, explica la doctora Hoyos, es deber de toda persona, deber de índole no sólo moral, sino jurídico, respetar los derechos ajenos y no abusar de los propios (art. 95 ibídem), así como procurar el cuidado integral de su salud y la de su comunidad (art. 40 ibídem). Por tanto, añade la citada autora, "aceptar las tesis de la Corte Constitucional también significaría desconocer los deberes que le competen a un Estado que se dice Social de Derecho, entre estos deberes se debe mencionar el de proteger, no de desproteger, a las personas que por su condición física o mental se encuentren en

8 COLOMBIA. CORTE CONSTITUCIONAL. Sentencia C-239 de 1997. En: CD-ROM Jurisprudencia de la Corte Constitucional, editado por la División de Sistemas de la Corporación. Bogotá, D.C., 2001. 
circunstancias de debilidad manifiesta y el deber de sancionar los abusos o maltratos que contra ellas se cometan."

Posteriormente, el 15 de agosto de 1997, el Rector y actual Decano de la Facultad de Derecho de la Universidad de La Sabana, doctor Álvaro Mendoza Ramírez, publicó en el Diario El Tiempo, un artículo titulado "Curioso pluralismo el de la Corte", que sería reproducido en 1 Boletín Informativo Mensual Infoprensa de septiembre de 1997. En dicho artículo, Mendoza dice:

"Oíamos hace algunos días, con asombro y con preocupación, al distinguido jurista que sirvió como ponente de una decisión mayoritaria de la Corte Constitucional sobre el tema de la eutanasia, afirmar en defensa de la decisión tomada que una creencia religiosa no podía imponerse a los no creyentes de la respectiva confesión, por ser éste un país apoyado en un sistema pluralista. Por otra parte, la línea argumental de la sentencia, que es de su autoría, se apoya en buena parte en la defensa del derecho a la autodeterminación.

Curiosos criterios los anteriores, que hieren las más arraigadas concepciones filosóficas de quienes, como yo, hemos encanecido trajinando por los terrenos del derecho y por los de su enseñanza.

¿Puede acaso un pretendido pluralismo admitir que el derecho a la autodeterminación carece de límites? De no aceptarse éstos ¿en qué quedan las reglas jurídicas, que no son, en buena parte, otra cosa que linderos establecidos a la autodeterminación, para impedir que ésta afecte los derechos de los demás y los de la sociedad?

Precisamente, nuestra Carta Magna, cuya defensa y cuya custodia se confió a la Corte Constitucional, que hoy mayoritariamente sienta tan peregrinas tesis, establece toda una serie de principios y de derechos fundamentales que deben servir de basamento a nuestro régimen jurídico, que son inviolables y que constituyen otras tantas talanqueras a la abusiva autodeterminación de los individuos. Entre otras, el respeto por la vida humana, concebido en forma absoluta $y$ sin excepciones como aquellas que ahora se pretende introducir.

Un Estado social de derecho, como lo pregona el primero de los artículos de la Constitución Nacional, es lo más opuesto que puede darse a un Estado individualista, en el cual las personas pueden pasar por sobre los derechos de la sociedad, so pretexto de una autodeterminación que, cuando traspasa ciertos linderos, se convierte en injurídica $y$ debe ser reprimida.

Por otra parte, para defender el pluralismo que alega la sentencia y que invoca su inspirado, se llega al contrasentido de que un grupo muy reducido de personas, únicamente seis, imponga una determinada valoración ética a toda una sociedad y desconozca las claras intenciones de un texto legal votado por un parlamento que, bien o mal, interpreta en nuestro sistema democrático el sentir del país al cual representa.

Lo que ha dicho la decisión mayoritaria de la Corte Constitucional es imponer a la nación entera un texto legal inexistente, contrario por lo demás a la Carta Magna, al cambiar o limitar el claro sentido de aquel declarado exequible demanera condicionada, y asumir asi un papel que no le correspondia, como lo destacan los valerosos salvamentos de voto presentados por tres magistrados.

En este caso, como en otro anterior relativo a la dosis personal de estupefacientes, la Corte no ha cumplido con su papel de confrontar los textos constitucionales con los de carácter legal, sino que ha impuesto al 
país unas valoraciones éticas determinadas, que corresponden al juicio personalísimo $y$ por demás controvertible de la mayoría de la Corte.

Curioso pluralismo este que pretende afirmarse al margen de la voluntad de los órganos democráticos, en contravía de la conciencia ética de un país y sostenido por un grupo reducido de magistrados que imponen su personal criterio."

Formulemos de nuevo estas preguntas elaboradas por José Luis del Barco: ¿Sirve el utilitarismo para resolver los conflictos bioéticos y biojurídicos? ¿Es capaz de establecer los límites seguros de las nuevas técnicas biomédicas? ¿Qué intervenciones en el hombre son legítimas y cuáles no? ¿Proporciona a la Bioética, a esta nueva y complejísima disciplina, un guía segura para solucionar sus difíciles problemas? La respuesta a estos interrogantes, como se desprende de lo que llevamos dicho, sólo puede ser negativa.

"El hombre entra en sociedad como miembro engendrado y nacido, no como socio fabricado y escogido. El ser humano es titular de derechos por su propia naturaleza, no tiene que agradecérselo a los demás. Cuando tiene lugar una intervención técnico-genética en el óvulo fecundado, incluso con una finalidad médica, no se cura a una persona existente, sino que se manipula su identidad". ${ }^{\text {. }}$

Por sugerencia del doctor Pablo Arango Restrepo, sólo he de referirme en este artículo para la Universidad Surcolombiana de Neiva, al llamado Derecho a la Salud, como se le conoce en la Constitución, aunque según precisiones del doctor Pedro José Sarmiento Medina, la salud no es un derecho sino un estado biológico, cuya protección está a cargo de la Nación, o también es, según Ilva Myriam $\operatorname{Hoyos}^{10}$, una de esas realidades que expresan de manera muy peculiar el mismo ser del hombre, porque se predica de un ser vivo que al perder la salud puede morir o enfermar. Vida y salud son como expersión de una misma realidad porque se corresponden mutuamente: sin un mínimo de salud no tengo vida y sin vida no tengo salud... Es por ello que la salud no es mera biología, sino que s un bien de carácter personal que le es inherente a todo ser humano.

Restringiendo el tema a la salud, a ese deber de procurar su cuidado integral, como lo impone como dimensión ética para ella nuestra Constitución Política, quisiera presentar a Ustedes, una relación de sentencias, no sin antes reseñar de la obra de la doctora Ilva Myriam Hoyos ${ }^{11}$, las características propias del derecho a la salud, cuyo núcleo esencial es la plenitud vital y derivadas de varias sentencias de la Corte Constitucional:

A. Es un derecho fundamental por ser inherente a la dignidad de la persona humana, en tanto que constituye parte integral de su ser.

B. Es un derecho derivado de la vida, porque la conexidad entre la salud y la vida es evidente ya que la salud es un objeto jurídico concreto del derecho a la vida.

D. Es un derecho que se tiene desde la concepción hasta la muerte.

C. Es un derecho que implica una acción de conservación y otra de restablecimiento que conlleva a la necesaria labor preventiva contra los posibles atentados a la salud,

9 REITER, J. Medicina predictiva - Análisis del genoma- Terapia genética. En: R. Low y otros, Bioética. Consideraciones filosoficoteológicas sobre un tema actual, Rialp, Madrid, 1992, página 93. Citado por DEL BARCO COLLAZOS, José Luis, Artículo citado, página 102.

10 HOYOS CASTANEDA, Ilva Myriam. La Persona y sus Derechos. Consideraciones Bioético-Jurídcas. Editorial Temis S.A. e Instituto de Humanidades de la Universidad de La Sabana, Bogotá, D.C., 2000, página 189.

11 HOYOS CASTANEEDA, Ilva Myriam. La Persona y sus Derechos. Ob. Cit., páginas 192 - 194 
así como a la protección de la normalidad orgánica funcional física y mental, y a su restablecimiento cuando se presente inestabilidad orgánica funcional y psíquica en el Ser.

E. Es un derecho que tiene como objeto la plenitud del Ser.

F. Es un derecho que implica hacer uso de los medios ordinarios y proporcionados para la prevención o recuperación de la salud, teniendo en cuenta la situación concreta del enfermo.

G. Es un derecho que, sin perder su carácter fundamental, tiene un carácter asistencial o prestacional.

Además del principio fundamental expresado en el deber de conservar la salud, según la ya citada doctora Hoyos, hay tres cuestiones esenciales a través de las cuales nuestra Carta Política desarrolla el tema de la salud:

Primera: el derecho fundamental a la salud, artículo 44 -que la Corte Constitucional, por razón de conexidad con la vida y otros derechos fundamentales ha considerado, respecto de toda persona, también derecho fundamental. Segunda: el deber de toda persona de procurar el cuidado integral de la salud de su comunidad, deber que se traduce en el obrar conforme al principio de solidaridadsocial, respondiendocon acciones humanitarias ante situaciones que pongan en peligro la vida o la salud de las personas -ordinal $2^{\circ}$ del artículo 95 constitucional. Y tercera: la atención a la salud, que debe ser garantizada por el Estado como servicio público. Cuestiones que plantean tres clases de relaciones que no pueden considerarse aisladamente: las relaciones de justicia conmutativa, las relaciones de solidaridad y las relaciones de justicia distributiva. ${ }^{12}$
En cuanto a la justicia conmutativa, vale decir que la salud es un bien que tiene como titular a toda persona. Ese bien que cada quien tiene es debido primariamente en una relación de justicia conmutativa por cualquier persona. Eso significa que cada ser humano tiene como algo suyo el bien de la salud y el de conservarla, recuperarla y acrecentarla, por tanto, el deber que tiene toda persona en relación con el derecho a la salud de otra es, en igual forma, una acción en orden al fin o al bien de la salud. De acuerdo con esto, nadie podrá afectar, aún con el consentimiento de su titular, la salud de otra persona.

En cuanto a la justicia distributiva, la pregunta radica en saber qué es lo que debe dársele a cada quien, cuál es la medida justa de la atención diferencial de una persona respecto de otra. Hasta dónde, cuál es el límite del trato distinto. Precisamente esto es lo propio de la justicia distributiva.

Y finalmente, en cuanto a las relaciones de solidaridad en el derecho a la salud, ésta se predica del mismo porque es la forma de promover, por parte del Estado, que las personas no sean indiferentes unas a otras y que verdaderamente se logre la promoción, protección y recuperación de la salud.

El gran inconveniente que tiene hoy la salud en Colombia, es que todos le huyen a su cumplimiento y sólo se logra acceder a ella a través de la Acción de Tutela. ¿Cuándo llegaremos al día en que no sea necesario "entutelar" para no morirnos?

\section{BIBLIOGRAFÍA}

\section{COLOMBIA. CORTE CONSTITUCIONAL.} Sentencia C-239 de 1997. En: CD-ROM Jurisprudencia de la Corte Constitucional, editado por la División de Sistemas de la Corporación. Bogotá, D.C., 2001. 
DEL BARCO COLLAZOS, José Luis. La Seducción Utilitaria. En: Anuario Filosófico XXVII, 1994, Universidad de Navarra, Pamplona.

DEL BARCO, José Luis en: Presentación del Anuario Filosófico Volumen XXVII/1, Universidad de Navarra.

GAVIRIA DÍAZ, Carlos Agapito. Fundamentos Ético-Jurídicos para despenalizar el homicidio piadosoconsentido. En: Jurisdicción Constitucional de Colombia. La Corte Constitucional 19922000, Realidades y Perspectivas. Editado por la Fundación Konrad Adenauer y la Escuela Judicial Rodrigo Lara Bonilla, Bogotá, D.C., febrero de 2001.

HOYOS CASTAÑEDA, Ilva Myriam. Los Principios de la Declaración del Genoma Humano y los Derechos Humanos. En: Pensamiento y Cultura \# 4, 2001, Universidad de La Sabana.

POLO, Leonardo. Presente y Futuro del Hombre, Rialp, Madrid, 1993, página 135. Citado por DEL BARCO, José Luis en: Presentación del Anuario Filosófico Volumen XXVII/1, Universidad de Navarra.

REITER, J. Medicina predictiva - Análisis del genoma- Terapia genética. En: R. Low y otros, Bioética. Consideraciones filosoficoteológicas sobre un tema actual, Rialp, Madrid, 1992, página 93. Citado por DEL HOYOS CASTAÑEDA, Ilva Myriam. La Persona y sus Derechos. Consideraciones Bioético-Jurídcas. Editorial Temis S.A. e Instituto de Humanidades de la Universidad de La Sabana, Bogotá, D.C., 2000. 